NASA Technical Memorandum 88888

\title{
A Heater Made From Graphite Composite Material for Potential Deicing Application
}

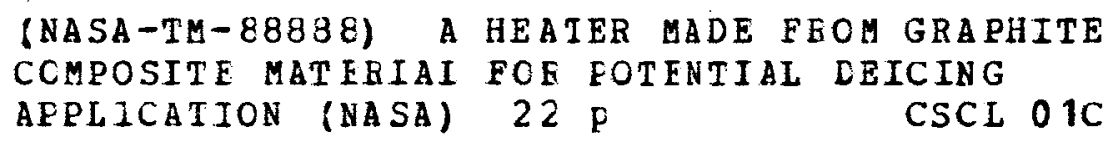

N $87-12559$

Unclas

G $3 / 05 \quad 44729$

Ching-Cheh Hung

Lewis Research Center

Cleveland, Ohio

and

Michael E. Dillehay and Mark Stahl

Cleveland State University

Cleveland, Ohio

Prepared for the

25th Aerospace Sciences Meeting

sponsored by the American Institute of Aeronautics and Astronautics

Reno, Nevada, January 12-15, 1987

\section{Mnsn}




\title{
A HEATER MAOE FROM, GRAPHITE COMPOSITE MATERIAL
}

FOR POTENTIAL DEICING APPLICATION

\author{
Ching-cheh Hung \\ National Aeronautics and Space Administration \\ Lewis Research Center \\ Cleveland, Ohio 44135 \\ and \\ Michael E. Dillehay and Mark Stahl \\ Cleveland State University \\ Cleveland, Ohio 44115
}

\section{SUMMARY}

A surface heater was developed using a graphite fiber-epoxy composite as the heating element. This heater can be thin, highly electrically and thermally conductive, and can conform to irregular surface. Therefore it may be used in aircraft's thermal deicing system to quickly and uniformly heat the aircraft surface. One-ply of unidirectional graphite fiber-epoxy composite was laminated between two plies of fiber glass-epoxy composite, with nickel foll contacting the end portions of the composite and partly exposed beyond the composites for electrical contact. The model heater used brominated $P-100$ fibers from Amoco. The fiber's electrical resistivity, thermal conductivity and density were $50 \mu \Omega-\mathrm{cm}, 270 \mathrm{~W} / \mathrm{m}-\mathrm{K}$ and $2.30 \mathrm{gm} / \mathrm{cm}^{3}$, respectively. The electricity was found to penetrate through the composite in the transverse direction to make an acceptably low foll-composite contact resistance. When conducting current, the heater temperature increase reached 50 percent of the steady state value within $20 \mathrm{sec}$. There was no overheating at the ends of the heater provided there was no water corrosion. If the foll-composite bonding falled during storage, liquid water exposure was found to oxidize the foil. Such bonding fallure may be avoided if perforated nickel foil is used, so that the composite plies can bond to each other through the perforated holes and therefore "lock" the foll in place. 


\section{INTRODUCTION}

Both military and civilian aircraft of the future will have an increasing number of components fabricated from composite materials. This motivation stems from not only the desire to reduce the aircraft weight, but also to make aircraft surface smoother, which could result in larger amount of laminar flow and hence less aircraft drag. If leading edges of lifting surfaces (1.e., wings and talls) and engine inlets are to be made from composite materials, then one problem which must be addressed is that of ice protection. Thermal anti/deicing systems which have been used for years by the aircraft industry ${ }^{1}$ does not appear to be useful for composite designs since composites characteristically have low thermal conductivities on the transverse direction and hence large amounts of heat would have to be provided to ensure that the outer surface reaches the required antf or defcing temperature.

However, this paper presents a concept for electric thermal anti/deicing of composite surfaces which seeks to solve the aforementioned problem. In particular, the use of thin graphite fiber composite for the heater is proposed. This thin heater has three unique features: highly electrically and thermally conductive graphite fibers are used in the composite material as the heating element, nickel foll is used as the electrical contact, and flexible prepreg (i.e., uncured composite) is used to conform to irregular surfaces and yield uniform heating. Such a design would allow the heater to be placed much closer to the exterior surface than would be the case with a more conventional electric thermal device for a composite instaliation.

Other advantages of this anti/deicing heater over previous ones will also be described in this report, along with the structure and design details of the model heater. 


\section{$\therefore$ APPARATUS AND PROCEDURE \\ Heater Materials and Design}

The basic design of the heater is 11lustrated in Fig. 1. One ply of highly electrically and thermally conductive graphite fiber composite was laminated between two plies of electrically insulating composite material, with nickel foil contacting the end portions of the graphite fibers. Part of the foil was exposed beyond the composite for an electrical contact. Several model heaters were fabricated to demonstrate the concept and perform the preliminary experiments. They were made from the materials described below.

Fiber-epoxy composite. The heating element was made of highly electrically conductive, brominated pitch based P-100 graphite fibers (Amoco Corporation). Bromination of the highly graphitized pitch based fibers was performed in this laboratory and the brominated fiber product has been studied extensively. The brominated fibers were shown to be stable in air up to $200{ }^{\circ} \mathrm{C}$, 100 percent humidity at $60^{\circ} \mathrm{C}$, vacuum, ${ }^{2}$ liquid water, and a variety of organic solvents. 3 Brominated $P-100$ fiber surfaces contain very little, if any, bromine. 4 The physical properties of pristine and brominated $\mathrm{P}-100$ fibers are described in Table 1. It is noted, from Table 1 , that the 10-percent decrease in thermal conductivity due to bromination is a result of the increase in the fiber cross-sectional area. This suggests that fiber structural damage due to bromination are very small.

The fiber-epoxy composite was made from the above fibers, with MY720 epoxy and HT976 hardener (Ciba-Geigy). It was cured at $177^{\circ} \mathrm{C}$ and 100 psi for 90 min. Some properties of the cured composite are listed in Table 2 . It is noted that a composite material with a 60 -percent volume of such fibers, has. a longitudinal electrical conductivity similar to a typical chrome-nickel 
heater, $^{13}$ and a longitudinal thermal conductivity about the same as

aluminum $6061,{ }^{7}$ or about ten times that of the typical chrome-nickel heating element.

Protective layers. The electricaliy insulating, protective layers were $0.15 \mathrm{~mm}$ thick fabric fiberglass-epoxy composite.

Nickel foll. The nickel foll, a product of AESAR, is 99-percent pure, $0.0254 \mathrm{~mm}$ thick, with an electrical resistivity of $6.8 \mu \Omega-\mathrm{cm} .^{14}$ The nickel foll was dipped in $\mathrm{HNO}_{3}$ for $5 \mathrm{sec}$ to remove any oxides on the foll surface prior to lamination.

Figure 2 is a photograph showing the three types of model heaters cut out of a $7.62 \times 20.32 \mathrm{~cm}$ composite, with the fibers in the $20.32 \mathrm{~cm}$ direction. All three heaters were $20.32 \mathrm{~cm}$ long and had $1.7 \mathrm{~mm}$ thick heating element. The top heater shown in Fig. 2 was used to conduct the heating performance experiment, was $1.3 \mathrm{~cm}$ wide with a $2.5 \mathrm{~cm}$ of fiber-foll overlap. The middle heater was $3.4 \mathrm{~cm}$ wide with a $1.3 \mathrm{~cm}$ overlap, and was used to conduct the corrosion experiment. The bottom heater was used as a control sample, and was $2.9 \mathrm{~cm}$ wide with a $1.3 \mathrm{~cm}$ overlap. In order to measure the voltage variation inside the composite, two narrow nickel foll pieces were laminated into the middle section of the top heater shown in Fig. 2 . These two folls were $7 \mathrm{~cm}$ apart. Sketches of the side view of this particular heater are shown in Figs. 3 and 4.

\section{Heating Performance Experiments}

\section{Electricity penetration across the graphite fibers in the composite. In} order to heat uniformly, the current density in the heater needs to be as uniform as possible, and the electricity penetration across the graphite fibers needs to reach completion before it conducts through a significant length of the composite. In the experiment to verify whether this is true, 
the heater shown in the top of Fig. 2 was connected to a current source (Keithley 225) and a voltmeter (Keithley 181) as described in Fig. 3 . The four contacts between the nickel foil and the wires (points A, B, C, and $D$ in Fig. 3) could be opened or closed according to the needs of the experiment. A constant current of $100 \mathrm{~mA}$ was conducted through the heater, via different combinations of contacts. The voltmeter readings were compared to each other to determine if the electricity penetrated through the composite in the transverse direction. In the region of the composite between the two voltmeter terminals, if the current conducting across the fiber did not reach completion, then the current density, and therefore the voltmeter readings, would not be a constant, but depend on which contacts the current conduct through.

Contact resistance. The heater shown in the top of $\mathrm{Fig} .2$ was also connected to the current source and the voltmeter as described in Fig. 4 . A constant current of $100 \mathrm{~mA}$ was conducted through the heater via the four foil contacts A, B, C, and D. One end of the voltmeter was connected to one end of the heater (1.e., points $A$ and $B$ ) while the other end of the voltmeter was connected to one of the two foll strips laminated into the middle section of the heater, or to the other end of the heater (i.e., points $E, F$, or $G$ ). These voltages, together with the zero voltage at one end of the heater (i.e., points $A$ and $B$ ), were plotted as a function of heater position. Since the resistance per unit length of the heater was uniform, the voltage was expected to be a linear function of position. The deviations of the measured nickel foll voltages from this linear function at the nickel foil's inner edge position were defined as the contact potential.

The contact potential divided by the current passing through the heater was defined as the contact resistance of the heater. 
Heating rate and temperature distribution. The heater shown at the top of Fig. 2 was heated at room environment by a $6 \mathrm{~A} \mathrm{dc}$ current at a voltage of $0.563 \mathrm{~V}$. The temperature of the heater was monitored by a noncontact IR thermometer. Temperature as a function of heating time was recorded at three different positions: the foll-composite overlap areas at both ends, and the center of the heater. The final, steady-state temperature was recorded at five different heater positions: the inside and outside edges of the folls at both ends, and the center of the heater.

Corrosion Experiment. The heater shown in the center of Fig. 2 was heated by a $20 \mathrm{~A}$ current at $0.65 \mathrm{~V}$ at room environment until the steady-state temperature was reached. The steady-state temperatures at the center and both ends of the heater were measured by an IR thermometer. This heater, together with the terminal wire, was then immersed in a container of tap water. It was heated in the water by a 20 A current for a few hours once every few days. The heater was then taken out of the water every 2 to 7 weeks, dried, and heated by a 20 A current at ambient conditions. The time schedule is shown in Table 3. The steady-state temperature at the center and both ends of the heater, and the potential difference between the foils at both ends of the heater were again measured. Comparison of the pre-and post-water immersion heating data described the extent of water corrosion.

RESULTS AND DISCUSSION

Advantages of the Composite Material Heater as a Deicer

The conventional deicing heater uses metal foll as the heating element. One of the disadvantages for the metal foil as heating element is that it does not have a good, durable bond to the protecting layer. The other disadvantage is that heating may not be uniform, resulting in cold spots which hold ice on the airplane, and hot spots which cause the ice to melt and refreeze at different sites. 
The composite-composite bonding in the composite material heater is more uniform and stronger than the composite-metal bonding found in conventional deicers. Good bonding and high thermal conductivity of the graphite fiber resuits in uniform heating.

The defcer needs to conform to irregularly shaped surface in order to heat the surface uniformly. The metal foll heating element in the conventional deicer is either flexible but fragile, or strong but inflexible. The composite heating element described here is both strong and, before curing, flexible. Therefore, it can conform to irregularly shaped large surfaces and yield uniform heating on such surfaces.

Due to the high electrical conductivity of the graphite fibers heating is achieved in the thin layer of heating element $(0.17 \mathrm{~mm}$ thick in the model heater) without using high voltage. Since the voltage drop across the heater is not high the thin protection layer can be used without dielectric breakdown.

Since the heater can be thin, the heat is applied directly to the region very close to the surface to be heated. Therefore the amount of heat accumulated by the composite heater is minimized, and the heating rate can be high despite the low transverse thermal conductivity. Also, since the heater can be thin, the electricity can penetrate through the heating element in the transverse direction despite the low transverse electrical conductivity.

Complete Electricity Penetration in the Transverse Direction

With a $100 \mathrm{~mA}$ current conducted through the heater described in Fig. 3 ,. the voltmeter readings obtained were found to have essentially the same value (3.545 mV) for all posstble combinations of contacts. Since nonuniform current density in the heater would result in different values of such voltmeter readings, it was concluded that the current density in the section of the heater between the two voltmeter terminals was a constant. Therefore, 
in this section of the heater, there was no transverse current, and the electricity penetration in the transverse direction was complete.

Electrical Resistivity and Heating Performance of the Model Heater

If $I$ is the current conducted through the heater, $E$ is the voltage drop across the heater, $P$ is the power per unit area of the heater, $\rho, L, W$ and $t$ are the resistivity, length, width, and thickness of the heater, then the equation relating the required power and the heater's resistivity and dimension is

$$
P L W=I E=\frac{I^{2} \rho L}{W t}
$$

Knowing that the heater described in $\mathrm{Fig} .3$ was $0.17 \mathrm{~mm}$ thick and $1.27 \mathrm{~cm}$ wide, the distance between the foil in the middle section of the heater was $7.0 \mathrm{~cm}$, and the voltmeter reading was $3.545 \mathrm{mv}$ when the current was $100 \mathrm{~mA}$, the resistivity of this particular composite was calculated to be $109 \mu \Omega-\mathrm{cm}$.

If the $0.17 \mathrm{~mm}$ thick heating element with a resistivity of $109 \mu \Omega-\mathrm{cm}$ is used to fabricate a $2.54 \mathrm{~cm}$ wide, $91.44 \mathrm{~cm}(3 \mathrm{ft})$ long deicer with $4.65 \mathrm{~W} / \mathrm{cm}^{2}$ power density $\left(30 \mathrm{~W} / \mathrm{in} .^{2}\right.$, the power density required for airplane defcing application), according to the above equation, the current conducting through and the voltage drop across the deicer would be $68 \mathrm{~A}$ and $15.8 \mathrm{~V}$, respectively.

\section{Contact Resistance}

Figure 5 shows the voltage as a function of position in the heater under a $100 \mathrm{~mA}$ current. This function is the straight line connecting the two middle data points in the plot. The straight line intercepts the nickel foil position (shaded area in Fig. 5) at points $A$ and $B$. The contact potential, or the deviation between the electrical potential represented by these two points and the measured nickel fotl potentials, were 0.62 and $0.68 \mathrm{mV}$. These contact potentials were equivalent to the voltage drop across 1.3 and $1.4 \mathrm{~cm}$ of this 
heater, respectively. Therefore, if the heaters are much longer than $1.4 \mathrm{~cm}$, the contact potential effects would not be significant.

The contact resistance (the ratio of contact potential to current) was $6.2 \times 10^{-3}$ and $6.8 \times 10^{-3} \Omega$ at the two ends of the heater, whose heating element was $1.27 \mathrm{~cm}$ wide, $0.17 \mathrm{~mm}$ thick, and had $2.5 \mathrm{~cm}$ overlap with the nickel foll.

It was noted that in a defective heater, the contact potential was equivalent to 10 to $15 \mathrm{~cm}$ composite length. This is much longer than the $1.4 \mathrm{~cm}$ described above and may result in overheating at the end portion of the heater if the foll-composite overlap is not long enough.

Heating Rate and Temperature Distribution

When the heater described above was heated starting at room temperature with a dc current of $6 \mathrm{~A}$ at a potential of $0.563 \mathrm{~V}$, the temperature rise near the two ends and at the center of the heater were monitored with time (Fig. 6). It was observed that the temperature increase reached 50 percent of its final, steady-state value in $20 \mathrm{sec}$. The steady-state temperature as a function of heater position is shown in Fig. 7. It was found that the heater was uniformiy heated except at the very edge of the heater, where a lower temperature was observed.

It was found from this and other unpublished experiments that the negative end of the heater (i.e., the end where electrons go to the graphite fibers from the nickel foil) is consistently hotter than the positive end of the heater (1.e., the end where electrons went to the nickel foll from the graphite fibers). This can be explained by the phenomenon that electron emission from a sharp surface (i.e., graphite fibers, $10 \mu \mathrm{m}$ diam) to a flat surface (1.e., nickel foil) requires less energy, or electric potential, than electron flow in the other direction. This argument suggests that at the 
negative end of the heater, most electrons are "emitted" from the inside edge of the nickel foll (25 $\mathrm{mm}$ thick) to the graphite fibers, while at the positive end of the heater, the electrons are "emitted" uniformly from the graphite fibers to the nickel foll. Thus the inside edge of the nickel foll at the negative end of the heater has the highest current density in the heater. The same argument suggests that using perforated foll at the negative end of the heater will increase the sharp edged region of the nickel foil. This may result in a more uniform distribution of the current density, and reduces the possibility of overheating at the inside edge of the foil.

Corrosion by Immersion in Water

Before immersing the heater shown in the middle of Fig. 2 in water, it was test heated by a $20 \mathrm{~A}$ current at $0.65 \mathrm{~V}$ in a room environment. The steadystate temperature at both ends and the center of the heater were 91, 90, and $75^{\circ} \mathrm{C}$, respectively. Knowing this composite was $3.4 \mathrm{~cm}$ wide, $0.17 \mathrm{~mm}$ thick and $17.8 \mathrm{~cm}$ long, and neglecting the contact potential, the resistivity of the composite was calculated to be $105 \mu \Omega-\mathrm{cm}$.

After immersing this heater into the water and taking it out once in 2 to 7 weeks to dry for heating test. The center and end temperatures and the voltage drop across the heater were recorded as functions of immersion time and heating time. The time schedule and results are shown in Table 3 . The voltage across the heater was found to inftially increase slowly, then accelerate. After 119 days of water corrosion and $79.5 \mathrm{hr}$ of $20 \mathrm{~A}$ current heating, some overheated spots on the heater started to turn brown during the dry heating test. At that time the voltage drop across the heater was $2.05 \mathrm{v}$. The center of this discolored, overheated part was the inner edge of the nickel foil at the negative end of the heater. This result agrees with the suggestion given earlier in this report, that the inner edge of the nickel foll at the negative end of the heater has the highest current density in the heater. 
For both the corrosion test sample and the control sample, the nickel foil was found to separate from the composite after some time of repeated mechanical handling and examination. But, unlike the corrosion test sample, the voltage across the control sample under a similar current density was found unchanged after 87 days of storage, and was not affected by foil-fiber separation. Therefore, it is believed that when the fiber and the foil start to separate, the water begins to oxidize the nickel foil, creating an electrically insulating layer on the foil, and therefore degrading the composite heater.

One method to avoid the foil-fiber separation is to use perforated nickel foll as an electrical contact. In this case the graphite fiber-epoxy composite and the fabric glass-epoxy composite can actually bond through the holes on the nickel foil, preventing the foil-fiber separation by "locking" the foil in place.

The behavior of heater temperature as a function of immersion time is not well understood. However, it was found that the center temperature was hotter than the end temperatures before the corrosion test experiments. After a long time in the water corrosion test though, the end temperature was about the same as the center temperature. This suggests that corrosion took place at the end portion of the heater, i.e., the place of foll and fiber contact.

\section{Alternative Materials}

The individual components of the heater were chosen to demonstrate the concept and perform the preliminary heating experiment. It is possible that alternative materials could be used. For example, the brominated P-100 fibers in the heating element could be replaced by other kind of highly electrical conductive fibers such as brominated $P-75$ fibers $^{15}$ or fluorine intercalated P-55 fibers. 16 This change would reduce the heater's cost, but would result in a higher electrical resistivity of the heating element. 
Nickel was used as the foll material, because it is relatively electrically conductive, more corrosion resistant than copper and aluminum, 17 and less expensive than precious metals. Titanium, monel, or stainless steel folls may be used, because they are more corrosion resistant and are known to be compatible with graphite, ${ }^{18}$ but they have a rather low electrical conductivity. Platinum and gold may be used because they are more corrosion resistant and electrically conductive, but they are much more expensive than nickel. Actual choice of the foil material may depend on a compromise between cost and durability in the functional environment of the particular application.

\section{High Temperature Composite Material Heater}

It is hoped that the heater described in this report can be used in other unidentified applications where fast and unform heating on large and irregularly shaped surfaces is necessary. In some applications, the heater temperature may need to be higher than the maximum operating temperature of both epoxy and brominated fibers $\left(200^{\circ} \mathrm{C}\right)$. For those applications epoxy needs to be replaced by other high temperature matrix materials such as polyimide or ceramic, and brominated fibers need to be isolated from the air and to be heated to the heater's operating temperature before fabrication. Unpublished data indicate that after heating brominated $P-100$ fibers in vacuum at 650 and $800{ }^{\circ} \mathrm{C}$ for 2 weeks, their resistivities become $83 \pm 8$ and $132 \pm 38 \mu \Omega-\mathrm{cm}$, respectively. Although this heating procedure significantiy increases the fiber resistivity, the fibers are still highly conductive. Therefore they are still applicable as the heating element in high temperature heaters.

\section{Future Work}

In the immediate future, the heater described above will be mounted on a model afrfoil to conduct icing experiments in Icing Research Tunnel at NASA 
Lewis Research Center. Also, additional experiments will be conducted to further examine the heaters made from different materials, and the foll-composite contact.

\section{CONCLUSION}

The composite material heater using brominated $P-100$ graphite fiber-epoxy as the heating element, fabric glass-epoxy as the protecting layer, and nickel foil as the electrical contact was demonstrated to have acceptable heating performance. The resistivity of the heating element was 105 to $109 \mu \Omega-\mathrm{cm}$, and the current density in the heater was uniform. For the $20.3 \mathrm{~cm}$ model heater used in heating performance experiment, the sum of the two foll-fiber contact potentials at the ends of the heater represented 14 percent of total heater voltage drop. Overheating due to poor electrical contact may occur if the heater is poorly fabricated or badly corroded. When current was conducted through a room temperature heater, its temperature increase reached 50 percent of the final steady-state value of $20 \mathrm{sec}$. Foll-fiber separation can cause high contact potentials, but might be prevented by using perforated nickel foll instead of plain foll.

\section{ACKNOWLEDGMENTS}

The authors appreclate the help of the following NASA Lewis Research Center scientists: Dr. J. Shaw, who gave valuable input on airplane deicing technology, Dr. R.D. Vannucci, who helped determine the processing method to fabricate the model heater, and Dr. D.A. Jaworske and Dr. J.R. Galer, who gave valuable suggestions throughout the duration of this project and helped develop the method to measure the specific heat. The authors also thank Mr. Pete Addante of NASA Lewis Research Center, for fabricating the model heaters, and Ms. C. Maciag of Cleveland State University, for conducting the specific heat measurement experiment. 


\section{REFERENCES}

1. Werner, J.B., "The Development of an Advanced Anti-Icing/Deicing Capability for U.S. Army Helicopters, Vol. 1; Design Criteria and Technology Considerations," USAAMRDL-TR-75-34A, Nov. 1975.

2. Gaier, J.R., "Stability of Bromine Intercalated Graphite Fibers," NASA TM-86859, 1984.

3. Dillehay, M. and Gaier, J.R., "The Milling of Pristine and Brominated P-100 Graphite Fibers," NASA TM-88828, 1986.

4. Jaworske, D.A. and Zinolabedini, R., "Graphite Fiber Intercalation: Dynamics of the Bromine Intercalation Process," NASA TM-87015, 1985.

5. "Thorne1 P-100 Carbon Fiber Grade VS-0054," Union Carbide Corporation, Bulletin No. 465-246.

6. Gaier, J.R. and Marino, D., "Homogeneity of Pristine and Bromine Intercalated Graphite Fibers," NASA TM-87016, 1985.

7. Hung, C.C. and Miller, J., "Thermal Conductivity of Pristine and Brominated P-100 Fibers," NASA TM-88863, 1986.

8. Miller, J. and Hung, C.C., NASA Lewis Research Center, Cleveland, $\mathrm{OH}$, unpublished data, 1985.

9. Hung, C.C., "A Micrographic and Gravimetric Study of Intercalation and Deintercalation of Graphite Fibers," NASA TM-87026, 1985.

10. Jaworske, D.A., Vannucci, R.D., and Zinolabedini, R., "Mechanical and Electrical Properties of Graphite Fiber Epoxy Composites Made From Pristine and Bromine Intercalated Fibers," to be published in Journal of Composite Materials, 1986.

11. Scola, D.A. and Pater, R.H., "The Properties of Novel Bisimide Amine Cured Epoxy/Cellion 6000 Graphite Fiber Composites," SAMPE Journal, Vol. 18, No. 1, Jan.-Feb. 1982, pp. 16-23. 
12. Maciag, C. and Hung, C.C., NASA Lewis Research Center, Cleveland, $\mathrm{OH}$, Unpublished Data, 1986.

13. Perry, J.H., Chemical Engineer's Handbook, 4th ed., McGraw H111, NY, 1973.

14. Handbook of Chemistry and Physics, 56th ed., 1975-1976, CRC Press, Boca Raton, FL, 1976.

15. Gaier, J.R. and Slabe, M.E., "Effects of Graphitization on the Environmental Stability of Brominated Pitch Based Fibers," to be presented at the Materials Research Society Meeting, Boston, MA, Dec. 1-6, 1986.

16. Hung, C.C. and Stahl, M., "Effects of Sequential Treatment with Fluorine and Bromine on Graphite Fibers," to be presented at the Carbon Conference of the American Carbon Society, Worcester, MA, July 1987.

17. Evans, U.R., The Corrosion and Oxtdation of Metals: Sctentific Princtples and Practical Applications, Edward Arnold LTD, London, 1960.

18. Plumer, J.A., Lightning Technologies, Inc., Pittsfield, MA, Personal. Communication, 1986. 
TABLE 1. - PROPERTIES OF PRISTINE AND BROMINATED P-100 FIBERS

\begin{tabular}{|c|c|c|}
\hline & $\begin{array}{l}\text { Pristine } \\
\text { P-100 }\end{array}$ & $\begin{array}{c}\text { Brominated } \\
\text { P-100 }\end{array}$ \\
\hline $\begin{array}{l}\text { Electrical } \\
\text { resistivity } \\
\text { in fiber } \\
\text { direction, } \\
\mu \Omega-c m\end{array}$ & $\begin{array}{l}250 \\
\text { (Ref.5) }\end{array}$ & $\begin{array}{l}50 \\
(\operatorname{Ref} .6)\end{array}$ \\
\hline $\begin{array}{l}\text { Therma } 1 \\
\text { conductivity, } \\
\text { W/m-K }\end{array}$ & $\begin{array}{l}300 \\
\text { (Ref.7) }\end{array}$ & $\begin{array}{l}270 \\
\text { (Ref.7) }\end{array}$ \\
\hline Diameter, $\mu$ & $\begin{array}{l}9.1 \\
(\operatorname{Ref} .6)\end{array}$ & $\begin{array}{l}9.5 \\
(\operatorname{Ref} .6)\end{array}$ \\
\hline $\begin{array}{l}\text { Density, } \\
\mathrm{gm} / \mathrm{cm}^{3}\end{array}$ & $\begin{array}{l}2.18 \\
(\operatorname{Ref} .8)\end{array}$ & $\begin{array}{l}2.30 \\
(\operatorname{Ref} .8)\end{array}$ \\
\hline $\begin{array}{l}\text { Bromine/Carbon } \\
\text { weight ratio }\end{array}$ & 0 & $\begin{array}{l}0.18 \\
(\operatorname{Ref} .9)\end{array}$ \\
\hline $\begin{array}{l}\text { Specific heat, } \\
\text { cal/gm- }{ }^{\circ} \mathrm{C}\end{array}$ & $\begin{array}{l}0.17 \\
\text { (Ref.12) }\end{array}$ & $\begin{array}{l}0.20 \\
(\operatorname{Ref} .12)\end{array}$ \\
\hline
\end{tabular}

TABLE 2. - TRANSPORT PROPERTIES OF THE BROMINATED P-100 FIBER-EPOXY COMPOSITES WITH 60 PERCENT FIBER VOLUME FRACTION

\begin{tabular}{|c|c|c|}
\hline & $\begin{array}{l}\text { Longitudinal } \\
\text { direction }\end{array}$ & $\begin{array}{l}\text { Transverse } \\
\text { direction }\end{array}$ \\
\hline $\begin{array}{l}\text { Electrical } \\
\text { resistivity, } \\
\Omega-c m\end{array}$ & b8 $8 \times 10^{-6}$ & $\begin{array}{l}0.5 \\
(\text { Ref. 10) }\end{array}$ \\
\hline $\begin{array}{l}\text { Thermal } \\
\text { conductivity, } \\
W / m-K\end{array}$ & $\begin{array}{l}162 \\
\text { (Ref.8) }\end{array}$ & $\begin{array}{l}2.2 \\
\text { (Ref.8) }\end{array}$ \\
\hline $\begin{array}{l}\text { Density, } \\
\mathrm{g} / \mathrm{cm}^{3}\end{array}$ & $a_{1} .90$ & $\mathrm{a}_{1} .90$ \\
\hline $\begin{array}{l}\text { Specific } \\
\text { heat, } \\
\text { cal/gm-k }\end{array}$ & $\begin{array}{l}0.22 \\
(\text { Ref.12) }\end{array}$ & $\begin{array}{l}0.22 \\
\text { (Ref.12) }\end{array}$ \\
\hline $\begin{array}{l}\text { Thermal } \\
\text { diffusivity, } \\
\mathrm{cm}^{2} / \mathrm{sec}\end{array}$ & 0.93 & 0.013 \\
\hline \multicolumn{3}{|c|}{$\begin{array}{l}\text { acalculated value } \\
\text { (fiber density }=2.30 \mathrm{~g} / \mathrm{cm}^{3} \text {, Ref. } 8, \\
\text { epoxy density }=1.30 \mathrm{~g} / \mathrm{cm}^{3}, \text { Ref. } 11 \text { ) } \\
\text { bCalculated value } \\
\text { (fiber resistivity }=50 \mu \Omega-\mathrm{cm} \text {, Ref. } 6 \text { ) }\end{array}$} \\
\hline
\end{tabular}




$$
\because *
$$

TABLE 3. - POTENTIAL DIfFERENCE BETWEEN THE ENDS, AND TEMPERATURE

AT THE CENTER AND BOTH ENDS OF THE 3.4 CM WIDE HEATER WHILE UNDER DRY HEATING TESTS AT A 20 A CURRENT

\begin{tabular}{|c|c|c|c|c|c|}
\hline $\begin{array}{c}\text { Total } \\
\text { duration } \\
\text { in water, } \\
\text { day }\end{array}$ & $\begin{array}{c}\text { Total } \\
\text { duration } \\
\text { with 20 A } \\
\text { applied current, } \\
\text { hr }\end{array}$ & $\begin{array}{c}\text { End-to-end } \\
\text { potential } \\
\text { difference, } \\
\text { V }\end{array}$ & $\begin{array}{c}\text { Center } \\
\text { temp., } \\
\text { C }\end{array}$ & $\begin{array}{c}\text { End 1 } \\
(-) \text { temp. } \\
\text { C }\end{array}$ & $\begin{array}{c}\text { End 2 } \\
(+) \text { temp., } \\
\text { C }\end{array}$ \\
\hline 0 & 0 & 0.65 & 91 & 90 & 75 \\
12 & 6 & 0.65 & 90.5 & 84 & 82 \\
59 & 7 & 0.69 & 86 & 86.5 & 80 \\
73 & 28.8 & 0.73 & 88.4 & 78 & 86 \\
87 & 59.2 & 0.95 & 94 & 94 & 90 \\
119 & 79.5 & 2.05 & & & \\
\hline
\end{tabular}




\section{Coicinal PACE IS \\ OF POOR QUALTY}

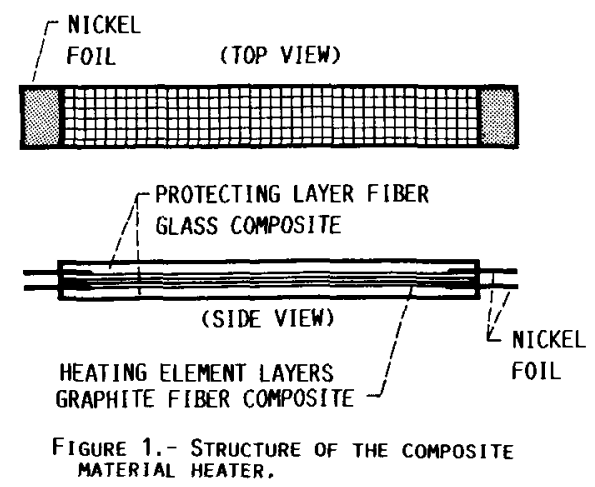

IgURE 1.- STRUCTURE OF THE COMPOSITE
MATERIAL HEATER.

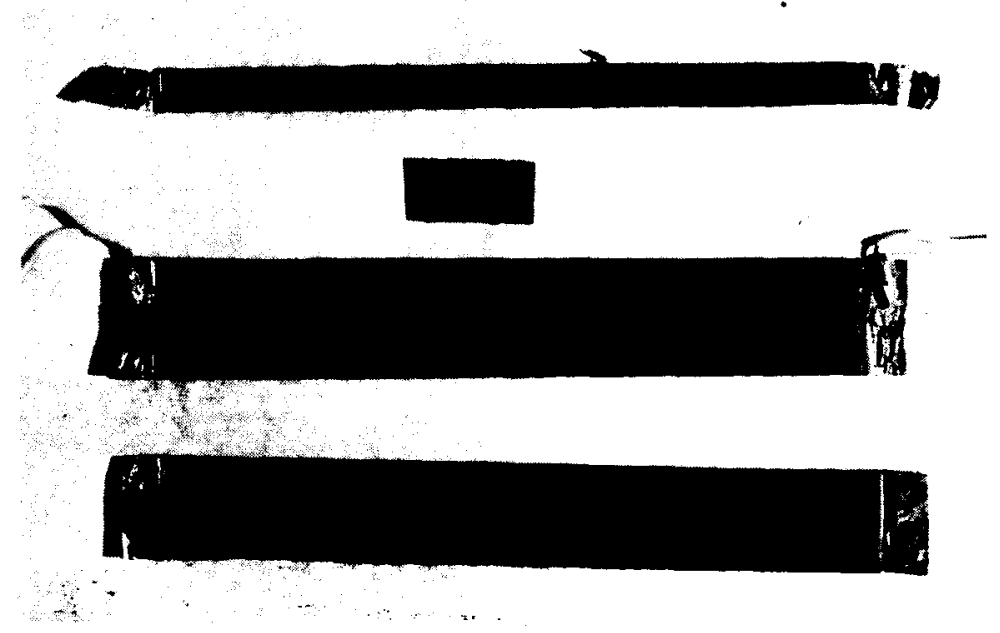

Figure 2.- Model heaters used in the testing. Top: heater FOR hEATING PERFORMANCE EXPERIMENT. MIDDLE: heATER FOR CORROSION TEST. BOTTOM: CONTROL SAMPLE. 


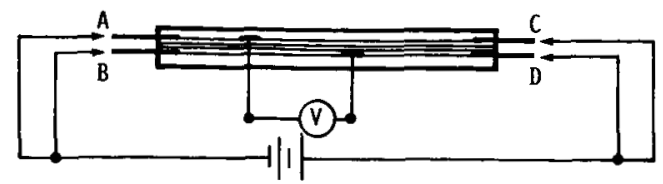

FIGURE 3.- ELECTRICAL CIRCUIT USED TO TEST THE ELECTRICITY PENETRATION IN THE TRANSVERSE DIRECTION.

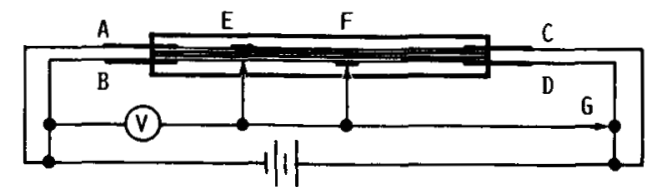

FIgURE 4. - ELECTRICAL CIRCUIT USED TO ESTIMATE THE CONTACT RESISTANCE BETWEEN THE FOIL AND THE COM-
POSITE.

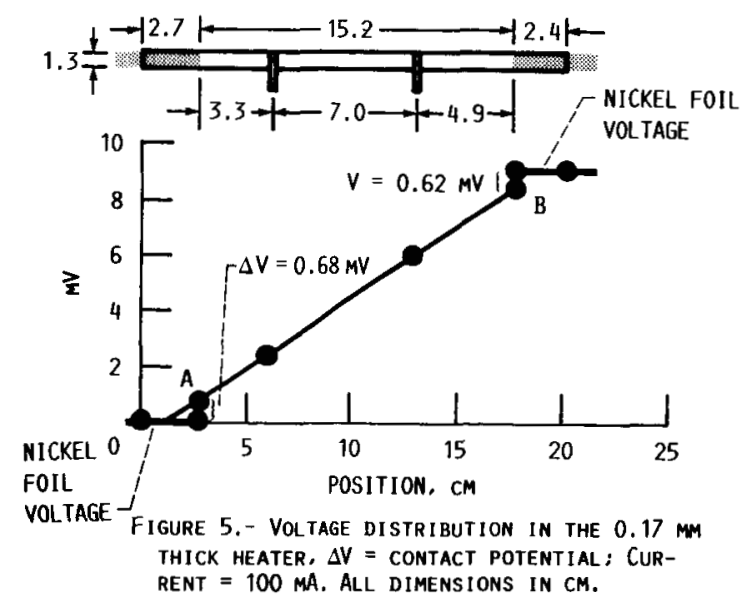




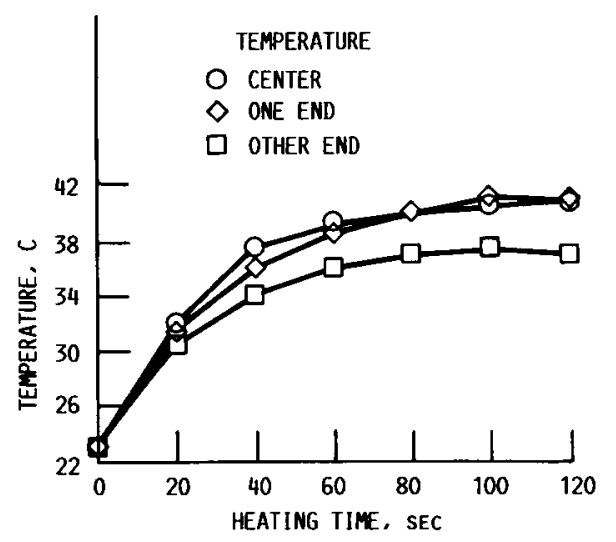

Figure 6.- TEMPERATURE NEAR THE TWO ENDS

AND AT THE CENTER OF THE HEATER AS A

FUNCTION OF T

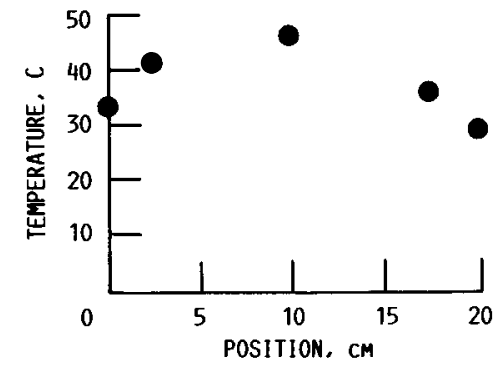

FIGURE 7.- STEADY STATE TEMPER-

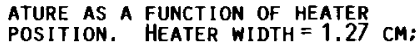
CURRENT $=6$ A 


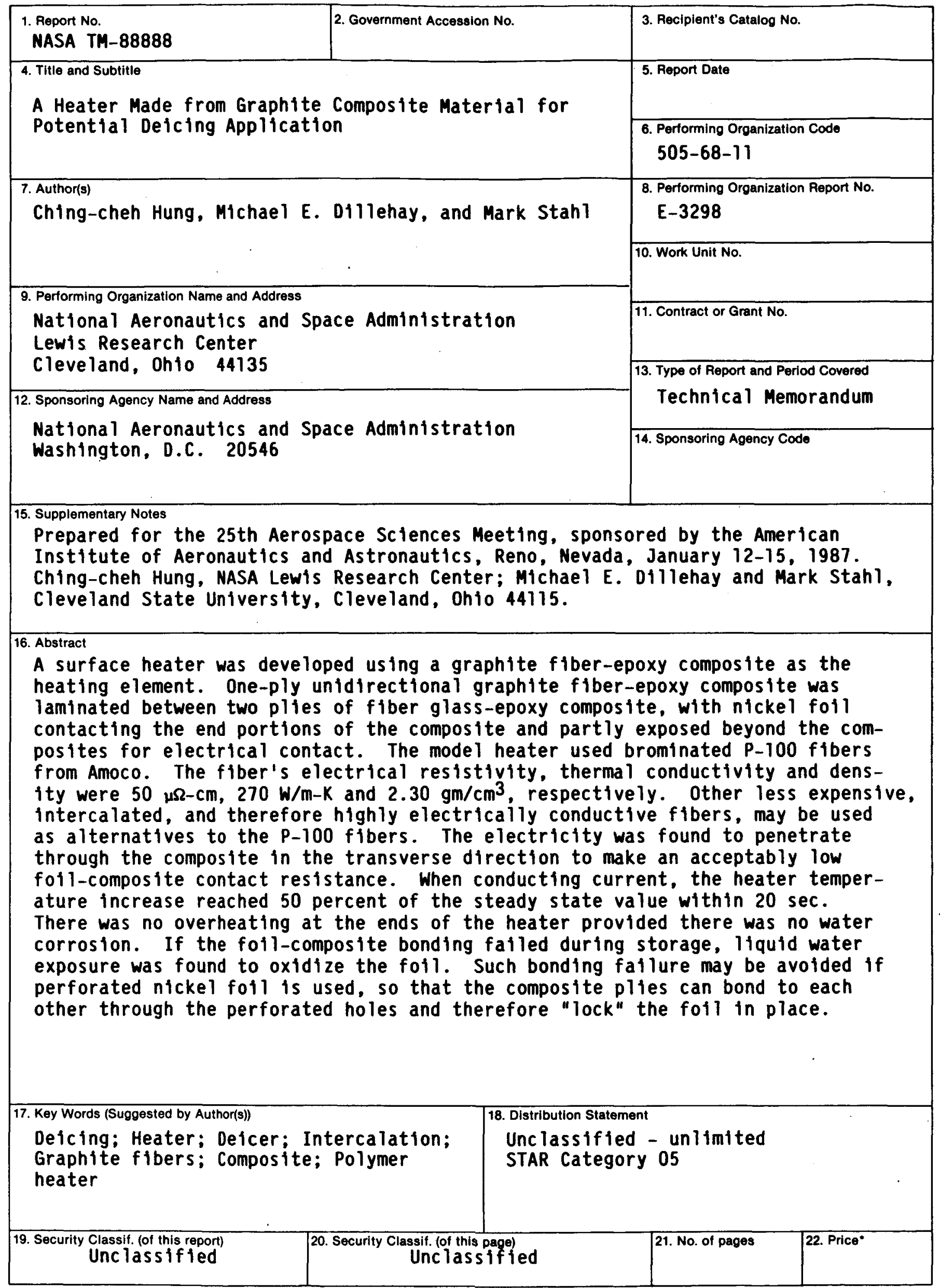

"For sale by the National Technical Information Service, Springfield, Virginia 22161 